\title{
Tigecycline treatment of infection caused by KPC-producing Escherichia coli in a pediatric patient
}

\author{
Xiaoxing Du, Ying Fu and Yunsong Yu*
}

\begin{abstract}
Tigecycline shows great antimicrobial activity against both Gram-positive and Gram-negative bacteria, and has been considered to be an appropriate choice in controlling infection caused by multi-drug resistant (MDR) pathogens, such as carbapenemase-producing Enterobacteriaceae (CPE). Although many clinical trials evaluate the efficacy and safety of tigecycline on adults, rare reports recommend tigecycline to treat pediatric patient. In this study, we presented a clinical case with tigecycline as an anti-infectious agent on a 14-year-old child who was suffering from infection of intraperitoneal abscess caused by Klebsiella pneumoniae carbapenemases (KPC)-producing Escherichia coli with extreme drug resistant profile. By accessing the clinical outcome and efficacy of the patient, and the side effects of tigecycline, our research explored the documented experience of tigecycline on controlling infection caused by CPE isolate in children.
\end{abstract}

Keywords: Tigecycline, Treatment, KPC, Pediatric patient

\section{Introduction}

Carbapenems have been considered to be the last-line antimicrobial agents to against multiple drug resistant (MDR) Gram-negative bacteria for a long time. While recently, the emergence of carbapenemase-producing Enterobacteriaceae (CPE) has been reported worldwide increasingly, which has raised global concern for those isolates shows hydrolytic activities to multiple antibiotics including carbapenems [1-3]. There are many carbapenemases involved in CPE isolates, in which Klebsiella pneumoniae carbapenemases (KPCs) plays a vital role [1-3]. Although the susceptibility data in vitro indicate that colistin, tigecycline, and fosfomycin are effective to CPE isolates, the optimal treatment choice hasn't reached agreement yet [2]. Among the above three selectable agents, tigecycline, a semi-synthetic derivative of minocycline and a member of the tetracycline family, shows superiority due to a wider anti-bacterial spectrum especially to MDR pathogens and better tissue permeability particularly to complicated intra-abdominal infection (cIAI) $[4,5]$. In practice, tigecycline has been approved to

\footnotetext{
*Correspondence: yvys119@163.com

Department of Infectious Diseases, Sir Run Run Shaw Hospital, College of Medicine, Zhejiang University, Hangzhou, Zhejiang, China
}

treat infection caused by MDR Gram-negative pathogen, especially for the care of critically ill patients [6]. However, it is still not been recommended to be used in pediatric patients, not mention to treat infection caused by $b l a_{\mathrm{KPC}}$-positive isolates. We reported here a documented case about a 14-year-old child who was infected by KPC-producing Escherichia coli and was treated with tigecycline.

\section{Case report}

On September 13, 2012, a 14-year-old Chinese patient was transferred to our hospital (Sir Run Run Shaw Hospital, Hangzhou, Zhejiang province, China) due to postoperative intraperitoneal abscess infection of appendicitis.

Three weeks ago (August 25, 2012), the patient was admitted to a local hospital of Hangzhou for vague abdominal pain of the right lower quadrant for one day. The pain was aggravated while walking, but was relieved when lying with knees bent. Total leukocyte count was $11.5 \times 10^{9} / \mathrm{L}$ with $63.7 \%$ neutrophils, his hemoglobin was $13.2 \mathrm{~g} / \mathrm{dL}$, and platelet count was $229 \times 10^{9} / \mathrm{L}$. The clinical diagnosis of acute appendicitis was confirmed by the B-ultrasonography. Then appendectomy was conducted immediately. While just after the operation, the patient 
developed severe pain at incision site with frequent chills and fever (over $39^{\circ} \mathrm{C}$ ). The complete blood count $(\mathrm{CBC})$ results indicated that the leukocyte count increased to $14.3 \times 10^{9} / \mathrm{L}$ with $91.5 \%$ neutrophils, and C-reactive protein (CRP) level arrived to $523 \mathrm{mg} / \mathrm{L}$. The patient received aztreonam $(1 \mathrm{~g} \mathrm{q} 12 \mathrm{~h})$ and etimicin sulfate $(0.2 \mathrm{~g} \mathrm{qd})$ to control postoperative infection for two days, while he persisted with high fever and further developed to lower back pain, accompanied with nausea, vomiting (two to three times per day) and diarrhea (six to seven times per day). Considering the anti-infective effect unsatisfied, moxalactam (latamoxef, $1 \mathrm{~g}$ q12h) was prescribed to the patient on the forth hospital day. At this time, computed tomography (CT) scan was conducted, which indicated seroperitoneum, pneumatosis, swelling of soft tissue near right psoas, right kidney enlargement and pleural effusion. Leukocyte count was still high as $12.3 \times 10^{9} / \mathrm{L}$ with $78.3 \%$ neutrophils, and CRP was $96.1 \mathrm{mg} / \mathrm{L}$. Antibiotic treatment was then switched to imipenem $(0.5 \mathrm{~g} \mathrm{q} 8 \mathrm{~h})$ on the fifth hospital day. The temperature could be controlled within $37.5^{\circ} \mathrm{C}$ to $38^{\circ} \mathrm{C}$ during the usage of imipenem. Two weeks later, the patient deteriorated to incision suppurates and was transferred to our hospital for further treatment.

Physical examination showed that abdomen was soft and flat, tenderness and rebound tenderness were positive around the incision site. A $3 \mathrm{~cm}$-long incision in the right lower quadrant was swelling and purulent. Percussion pain of the right renal region was positive. The leukocyte count was $10.0 \times 10^{9} / \mathrm{L}$ with $6.5 \%$ neutrophils, $70.7 \%$ lymphocytes, and $21 \%$ monocytes. The hemoglobin, platelets, CRP and procalcitonin $(\mathrm{PCT})$ were $10.7 \mathrm{~g} / \mathrm{dL}, 117 \times 10^{9} / \mathrm{L}, 116.7 \mathrm{mg} / \mathrm{L}$ and $2.3 \mathrm{ng} / \mathrm{ml}$, respectively. CT scan showed abscesses spread to right paracolic sulcus, iliaca fossa and liver. On September 14 (the second hospital day in our hospital), the patient's condition was suddenly worsened, with blood pressure and $\mathrm{SaO}_{2}$ down to $70 / 40 \mathrm{mmHg}$ and $90 \%$, heart rate and respiratory rate up to 130 beats and 25 per minute, which suggested sepsis shock happened. The patient received the second abdominal surgery immediately to repair intestinal fistula. Two E. coli isolates were isolated from continual abdominal effusion culture, both of which were pan-resistant to antimicrobial agents by VITEK 2 system, but susceptible to tigecycline, colistin and fosfomycin with MIC $0.25 \mathrm{mg} / \mathrm{L}, 0.5 \mathrm{mg} / \mathrm{L}$ and $16 \mathrm{mg} / \mathrm{L}$ using E-test method, respectively (Table 1). According to the susceptibility result, it seemed that only three antibiotics could be used in this case, while colistin is unavailable in China mainland nowadays. It is highly recommended that fosfomycin be used in combination with other agents for the treatment of infections with CPE to prevent the emergence of resistance to this agent [7], so the combination of tigecycline (first dose of $100 \mathrm{mg}$, then $50 \mathrm{mg} \mathrm{q12h}$, according to $1 \mathrm{mg} / \mathrm{kg}$ body weight) and intravenous fosfomycin (4 g q12h) was given to the patient. But fosfomycin had to be stopped in the next day due to its adverse reaction (serious vomiting). Six days after the usage of tigecycline, a Enterobacter cloacae isolate resistant to tigecycline with MIC $4 \mathrm{mg} / \mathrm{L}$ but susceptible to most $\beta$-lactam antibiotics was separated (Table 1), then the antibiotic treatment was switched to cefepime ( $2 \mathrm{~g} \mathrm{q12h}$ ). Leukocyte count decreased to $8.1 \times 10^{9} / \mathrm{L}$ with $34.1 \%$ neutrophils, $39 \%$ lymphocytes, and $26.5 \%$ monocytes, and CRP to $9 \mathrm{mg} / \mathrm{L}$. On the 13th hospitalization day in our hospital, the patient was improved greatly and then discharged.

Genes associated with carbapenems resistance were detected on the above two $E$. coli isolates, as previous reported, which showed both of them carried $b l a_{\mathrm{KPC}-2}$ and $b l a_{\text {CTX-M-24 }}$ gene $[8,9]$.

\section{Discussion}

KPC-producing Enterobacteriaceae, as one of MDR pathogens associated to healthcare-associated infection (HCAI) with high mortality, has raised global concern for the outbreaks in northeast of USA, Israel and the east China in recent years [1]. Enterobacteriaceae isolates carrying KPCs enzyme exhibit hydrolyzing-activity to wide spectrum of $\beta$-lactams, including penicillins, cephalosporins, aztreonam, and even carbapenems. Seriously, most of them usually co-harbor other resistant genes mediating resistance to multiple classes of antibiotics such as fluoroquinolones or aminoglycosides [3], which leads to MDR events. When CPE isolates evolve to MDR, clinical therapy would be immersed to serious situation. The combination of different antibiotics with synergistic mechanisms of action not only may be useful for the management of multidrug-resistant Gram-negative infections but also can lessen the chance of resistance development.

Reports have given some suggestions on combination schemes to CPE isolates [10]. Based on the synergic effect between third generation cephalosporins and amoxicillin/ clavulanic acid to KPC producers in vitro, some experts consider cephalosposins like cefepime in combination with amoxicillin/clavulanic acid could produce well effect, but it

Table 1 The susceptibility results

\begin{tabular}{|c|c|c|c|c|c|c|c|c|c|c|c|c|}
\hline Isolates & TZP & AMK & CRO & FEP & GEN & CPS & ETP & IPM & MEM & TGC & CST & FOM \\
\hline E. coli (isolate 1 and 2) & $\geq 128$ & $\geq 64$ & $\geq 64$ & 64 & $\geq 16$ & 96 & $\geq 8$ & $\geq 16$ & 8 & 0.25 & 0.5 & 16 \\
\hline E. colace (isolate 3 ) & $\leq 4$ & 2 & $\leq 1$ & $\leq 1$ & $\leq 1$ & 0.19 & $\leq 0.5$ & 2 & 0.064 & 4 & 24 & 8 \\
\hline
\end{tabular}

Note: TZP, piperacillin/tazobactam; AMK, amikacin; CRO, ceftriaxone; FEP, cefepime; GEN, gentamicin; CPS, cefoperazone/sulbactam; ETP, ertapenem; IPM, imipenem; MEM, meropenem; TGC, tigecycline; CST, colistin; FOM, fosfomycin. 
is still lack of clinical evidence [11]. Besides, colistin, tigecycline and fosfomycin also show pretty well susceptibility to CPE in vitro. Combination therapy based on tigecycline or colistin is considered to be one of the other appropriate choice $[12,13]$. To those isolates with lower carbapenems MICs, combination based on carbapenems would also be effective. In our case, owning to the very slight synergic effect of cefepime in combination with amoxilin/ clavulanic acid observed in vitro, colistin being unavailable in China mainland and high level of carbapenems MICs (IMP $\geq 16$ ), tigecycline combined with fosfomycin seems to be our unique treatment option.

The activity of tigecycline in vitro has been recognized, and in vivo both the efficiency and the security of tigecycline are confirmed supportive, especially in community-acquired pneumonia (CAP), cIAI and complicated skin and skin structure infections (cSSSI) [14], but it has still not been recommended for the therapy on the pediatric population, even reports are rare. Among those rare reports, tigecycline was used to treat meningitis combined with bacteremia caused by vancomycin-resistant Enterococcus faecium and central venous catheter infection caused by MDR Corynebacter iumjeikeium, respectively $[15,16]$. In 2012, Halil Özdemir reported a nine-year-old girl with acute myeloid leukemia who was treated successfully with tigecycline due to multidrugresistant $E$. coli bacteremia [17]. Although some researches have explored for the treatment of infection involved by KPC-producing Enterobacteriaceae with tigecycline, the optimal therapy plan is yet to be established for the lack of the available clinical evidence in children reports.

In this case, we took tigecycline combined with fosfomycin as treatment option. The recommended dosage of tigecycline is calculated with $1.2 \mathrm{mg} / \mathrm{kg} \mathrm{q} 12 \mathrm{~h}$ (no more than $50 \mathrm{mg}$ ) in children. During the therapy, the patient developed vomiting, which it was thought to be related to fosfomycin at first, and hence fosfomycin was stopped. But this situation was not completely relieved until tigecycline was stopped. Therefore, it was very possible that the vomiting was related to tigecycline. It has been reported of the side-effect of vomiting involved by tigecycline that the phase II clinical trials revealed $50 \%$ children suffered from nausea and vomiting, majority of which were reported as mild to moderate in toxicity of tigecycline $[18,19]$. During the usage of tigecycline in our patient, an E. colace resistant to tigecycline was emerging, which presents the limitation of tigecycline. There several researches have reported monotherapy of tigecycline is restricted for treating infections, which involve with inducing resistant events and higher mortality [20-22]. Therefore, tigecycline may be used only as salvage therapy in critically ill patients, and if it is used for pediatric patients, more concerns should be taken because of possible side effects.

\section{Conclusion}

Owing to the limited evidence of tigecycline being used in pediatric patients, we did some documented experience to use monotherapy with tigecycline to treat KPC-producing Enterobacteriaceae infection in children. Our results confirmed the effect of tigecycline to control infection caused be CPE, while drug induced side effects like vomiting and inducing resistance were also observed during the therapy. Although infection was controlled successfully in this case, it is hard to evaluate the efficacy and the safety of tigecycline in treating pediatric patients, more concerns should be taken because of possible side effects.

\section{Consent}

Written informed consent was obtained from the patient for publication of this Case report and any accompanying images. A copy of the written consent is available for review by the Editor-in-Chief of this journal.

\section{Abbreviations}

MDR: multi-drug resistant; CPE: carbapenemase-producing Enterobacteriaceae; KPCs: Klebsiella pneumoniae carbapenemases; cIAl: complicated intra-abdominal infection; CBC: complete blood count; CRP: C-reactive protein; CT: computed tomography; PCT: procalcitonin; HCAl: healthcare-associated infection; CAP: community-acquired pneumonia; CSSSI: complicated skin and skin structure infections.

\section{Competing interests}

All authors do not have any potential, perceived, or real conflict of interest.

\section{Authors' contributions}

All authors made substantial contributions to the acquisition of data. DX assisted in data gathering and FY helped in drafting the manuscript. All authors read and approved the final manuscript prior to publication.

\section{Acknowledgment}

This project was supported by research grants from the Health Bureau of Zhejiang Province (no. 200708479).

Received: 4 June 2013 Accepted: 11 August 2013

Published: 13 August 2013

\section{References}

1. Nordmann P, Naas T, Poirel L: Global spread of Carbapenemase-producing Enterobacteriaceae. Emerg Infect Dis 2011, 17(10):1791-1798.

2. Qi Y, Wei Z, Ji S, Du X, Shen P, Yu Y: ST11, the dominant clone of KPC-producing Klebsiella pneumoniae in China. J Antimicrob Chemother 2011, 66(2):307-312.

3. Tzouvelekis LS, Markogiannakis A, Psichogiou M, Tassios PT, Daikos GL: Carbapenemases in Klebsiella pneumoniae and other Enterobacteriaceae: an evolving crisis of global dimensions. Clin Microbiol Rev 2012, 25(4):682-707.

4. Livermore DM: Tigecycline: what is it, and where should it be used? J Antimicrob Chemother 2005, 56(4):611-614.

5. Towfigh S, Pasternak J, Poirier A, Leister H, Babinchak T: A multicentre, open-label, randomized comparative study of tigecycline versus ceftriaxone sodium plus metronidazole for the treatment of hospitalized subjects with complicated intra-abdominal infections. Clin Microbiol Infect: the official publication of the European Society of Clinical Microbiology and Infectious Diseases 2010, 16(8):1274-1281.

6. Poulakou G, Kontopidou FV, Paramythiotou E, Kompoti M, Katsiari M, Mainas E, Nicolaou C, Yphantis D, Antoniadou A, Trikka-Graphakos E, et al: Tigecycline in the treatment of infections from multi-drug resistant gram-negative pathogens. J Infect 2009, 58(4):273-284. 
7. Falagas ME, Karageorgopoulos DE, Nordmann P: Therapeutic options for infections with Enterobacteriaceae producing carbapenem-hydrolyzing enzymes. Future Microbiol 2011, 6(6):653-666.

8. Shen P, Wei Z, Jiang Y, Du X, Ji S, Yu Y, Li L: Novel genetic environment of the carbapenem-hydrolyzing beta-lactamase KPC-2 among Enterobacteriaceae in China. Antimicrob Agents Chemother 2009, 53(10):4333-4338.

9. Pitout JD, Hossain A, Hanson ND: Phenotypic and molecular detection of CTX-M-beta-lactamases produced by Escherichia coli and Klebsiella spp. J Clin Microbiol 2004, 42(12):5715-5721.

10. Bush K: Bench-to-bedside review: The role of beta-lactamases in antibiotic-resistant Gram-negative infections. Crit Care 2010, 14(3):224.

11. Polsfuss S, Bloemberg GV, Giger J, Meyer V, Hombach M: Comparison of European Committee on Antimicrobial Susceptibility Testing (EUCAST) and CLSI screening parameters for the detection of extended-spectrum beta-lactamase production in clinical Enterobacteriaceae isolates. J Antimicrob Chemother 2012, 67(1):159-166.

12. Kelesidis T, Karageorgopoulos DE, Kelesidis I, Falagas ME: Tigecycline for the treatment of multidrug-resistant Enterobacteriaceae: a systematic review of the evidence from microbiological and clinical studies. J Antimicrob Chemother 2008, 62(5):895-904.

13. Hirsch EB, Tam VH: Detection and treatment options for Klebsiella pneumoniae carbapenemases (KPCs): an emerging cause of multidrug-resistant infection. J Antimicrob Chemother 2010, 65(6):1119-1125.

14. Cai Y, Wang R, Liang B, Bai N, Liu Y: Systematic review and meta-analysis of the effectiveness and safety of tigecycline for treatment of infectious disease. Antimicrob Agents Chemother 2011, 55(3):1162-1172.

15. Jaspan HB, Brothers AW, Campbell AJ, McGuire JK, Browd SR, Manley TJ, Pak D, Weissman SJ: Multidrug-resistant Enterococcus faecium meningitis in a toddler: characterization of the organism and successful treatment with intraventricular daptomycin and intravenous tigecycline. Pediatr Infect Dis J 2010, 29(4):379-381.

16. Dinleyici EC, Yargic ZA, Bor O, Kiremitci A, Durmaz G: Tigecycline treatment of multi-drug-resistant Corynebacterium jeikeium infection in a child with relapsing and refractory acute lymphoblastic leukemia. Pediatr Blood Cancer 2010, 55(2):349-351.

17. Ozdemir H, Ciftci E, Karbuz A, Oktay G, Aysev D, Yavuz G, Ince E: Successful treatment of multidrug-resistant Escherichia coli bacteremia with tigecycline in an acute myeloid leukemia child. Turk J Pediatr 2012, 54(1):59-60.

18. Prot-Labarthe S, Youdaren R, Benkerrou M, Basmaci R, Lorrot M: Pediatric acute pancreatitis related to tigecycline. Pediatr Infect Dis J 2010, 29(9):890-891.

19. Maximova N, Zanon D, Verzegnassi F, Granzotto M: Neutrophils engraftment delay during tigecycline treatment in 2 bone marrow-transplanted patients. J Pediatr Hematol Oncol 2013, 35(1):e33-e37.

20. Anthony KB, Fishman NO, Linkin DR, Gasink LB, Edelstein PH, Lautenbach E: Clinical and microbiological outcomes of serious infections with multidrug-resistant gram-negative organisms treated with tigecycline. Clin Infect Dis: an official publication of the Infectious Diseases Society of America 2008, 46(4):567-570.

21. Daly MW, Riddle DJ, Ledeboer NA, Dunne WM, Ritchie DJ: Tigecycline for treatment of pneumonia and empyema caused by carbapenemase-producing Klebsiella pneumoniae. Pharmacotherapy 2007, 27(7):1052-1057.

22. Qureshi ZA, Paterson DL, Potoski BA, Kilayko MC, Sandovsky G, Sordillo E, Polsky B, Adams-Haduch JM, Doi Y: Treatment outcome of bacteremia due to KPC-producing Klebsiella pneumoniae: superiority of combination antimicrobial regimens. Antimicrob Agents Chemother 2012, 56(4):2108-2113.

doi:10.1186/1476-0711-12-19

Cite this article as: Du et al:: Tigecycline treatment of infection caused by KPC-producing Escherichia coli in a pediatric patient. Annals of Clinical Microbiology and Antimicrobials 2013 12:19.

\section{Submit your next manuscript to BioMed Central and take full advantage of:}

- Convenient online submission

- Thorough peer review

- No space constraints or color figure charges

- Immediate publication on acceptance

- Inclusion in PubMed, CAS, Scopus and Google Scholar

- Research which is freely available for redistribution

Submit your manuscript at www.biomedcentral.com/submit
C Biomed Central 